\title{
Remote-only monitoring for patients with cardiac implantable electronic devices: a before-and-after pilot study
}

\author{
John A. Sapp BSc, Anne M. Gillis MD, Amir AbdelWahab MD MSc, Isabelle Nault MD, \\ Pablo B. Nery MD, Jeff S. Healey MD MSc, Satish R. Raj MD MSCI, Evan Lockwood MD, \\ Laurence D. Sterns MD, Samuel F. Sears PhD, George A. Wells PhD, Raymond Yee MD, \\ François Philippon MD, Anthony Tang MD, Ratika Parkash MD MS
}

\section{Abstract}

Background: Outcomes for patients with cardiac implantable electronic devices are better when follow-up incorporates remote monitoring technology in addition to in-clinic visits. For patients with implantable devices, we sought to determine the feasibility, safety and associated health care utilization of remote-only follow-up, along with its effects on patients' quality of life and costs.

Methods: This multicentre before-and-after pilot study involved patients with new or existing pacemakers or implantable cardioverter defibrillators. The "before" phase of the study spanned the period October 2015 to February 2017; the "after" phase spanned the period October 2016 to February 2018. The exposure was remote-only follow-up in combination with Remote View, a service that facilitates access to device data, allowing device settings to be viewed remotely to facilitate remote programming. Outcomes at 12 months were feasibility (adherence to remote monitoring), safety (rate of adverse events) and health care utilization (remote and in-clinic appointments). We also assessed quality of life, using 3 validated scales, and costs, taking into account both health care system and patient costs.

Results: A total of 176 patients were enrolled. Adherence (defined as at least 1 successful remote transmission during follow-up) was $87 \%$ over a mean follow-up of 11.7 (standard deviation 2.2) months. There was a reduction in in-clinic visits at specialized sites among patients with both implantable defibrillators (26 v. $5, p<0.001, n=48)$ and pacemakers $(42$ v. $10, p<0.001, n=51)$. There was no significant change in visits to community sites for patients with defibrillators (13 v. $17, p=0.3, n=48)$. The composite rate of death, stroke, cardiovascular hospitalization and device-related hospitalization was $7 \%(n=164)$. No adverse events were linked to the intervention. There was no change in quality-of-life scales between baseline and 12 months. Health care costs were reduced by $31 \%$ for patients with defibrillators and by $44 \%$ for those with pacemakers.

Interpretation: This pilot study showed the feasibility of remote-only follow-up, with no increase in adverse clinical outcomes and no effect on quality of life, but with reductions in costs and health care utilization. These results support progression to a larger-scale study of whether superior effectiveness and reduced cost can be achieved, with preservation of safety, through use of remote-only follow-up. Trial registration: ClinicalTrials.gov, no. NCT02585817

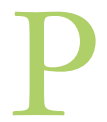

atients with cardiac implantable electronic devices (CIEDs) require follow-up for monitoring of device function and for device adjustment to optimize arrhythmia management. ${ }^{1-4}$ Practice guidelines in Canada recommend that patients undergo routine follow-up assessment of their devices at regular intervals $(6$ mo to $1 \mathrm{yr}$, depending upon the kind of device) to optimize device programming where clinically appropriate..$^{1-3}$ Follow-up should alternate between in-clinic and remote monitoring transmissions in a 1:1 ratio. ${ }^{3}$

Several early, predominantly single-centre cohort studies showed the potential benefits of remote monitoring for CIEDs, ${ }^{5-17}$ including significant reductions in the time required for device interrogation (with improved patient and clinician satisfaction), reductions in the number of inappropriate shocks delivered to patients with implantable cardioverter defibrillators (through earlier identification of lead or device failures) and earlier detection of atrial fibrillation and
Competing interests: For activities outside the work reported here, Jeff Healey has received personal fees from Boston Scientific, Medtronic, BMS/Pfizer and Cipher Pharma, as well as research grants from Abbott and ARCA Biopharma; Satish Raj has received personal fees from Lundbeck LLC, Theravance Biopharma, Spire Learning, Academy for Continued Healthcare Learning and Medscape; Evan Lockwood has received personal fees from Bayer, Pfizer and BMS; Samuel Sears has received research funding from Medtronic and Zoll Medical, as well as honoraria from Medtronic, Abbott/St. Jude Medical, Zoll Medical and Milestone Pharmaceutical; François Philippon and Anthony Tang have received research funding from Medtronic; and Ratika Parkash has received research funding from Novartis and Abbott. No other competing interests were declared.

Disclaimer: George Wells is a biostatistical consultant for CMAJ Open and was not involved in editorial decision-making for this article.

This article has been peer reviewed.

Correspondence to: Ratika Parkash, Ratika.parkash@nshealth.ca CMAJ Open 2021. DOI:10.9778/cmajo.20200041 
ventricular arrhythmia events. ${ }^{7}$ Benefits in relation to heart failure management have also been shown.

In patients with pacemakers, 2 multicentre randomized trials showed an increase in detection frequency of adverse clinical events and a reduction in reaction time to those events by remote monitoring. ${ }^{18,19}$ In patients with implantable cardioverter defibrillators, 4 randomized trials have assessed the efficacy of remote monitoring for reduction of in-clinic visits and earlier detection of clinical events without decreasing patient safety. ${ }^{20-23}$ All of these studies used a blended model to follow patients, and none of them used a remoteonly follow-up scheme.

Although remote monitoring technology is currently available for patients with access to a landline or mobile phone, its use has been inconsistent in Canada. As of 2013, only 8500 of a potential 120000 patients with devices had been enrolled in a remote monitoring program. ${ }^{24}$ This technology is in widespread use around the world; ${ }^{25}$ in Canada, it is used primarily for implantable defibrillators and not for pacemakers. ${ }^{26}$ Some patients may have difficulty attending a specialized device clinic in Canada because of geographic distance, burdensome cost of travel or constraints on access. In this pilot study, we sought to evaluate the feasibility, safety and utilization of a remote-only patient management system, along with its effects on patient quality of life and costs, which would reduce the need for in-clinic follow-up at specialty sites for patients with CIEDs.

\section{Methods}

\section{Setting and design}

We undertook this before-and-after pilot study to assess the feasibility, safety and health care utilization associated with a remote-only monitoring system for patients with Medtronic CIEDs. The study took place between October 2015 and February 2019. Patients were enrolled in the study between October 2016 and February 2018. For each patient, the "before" phase started 1 year before enrolment (i.e., October 2015 to February 2017), and the "after" phase began on the day of enrolment and lasted for 12 months (i.e., until February 2019 for those enrolled at the end of the enrolment period).

We planned to conduct this study at 5 Canadian centres with cardiac electrophysiologists on site: the Queen Elizabeth II Health Sciences Centre, Halifax; the Royal Jubilee Hospital/Victoria Cardiac Arrhythmia Trials, Victoria; the CK Hui Heart Centre, Royal Alexandra Hospital, Edmonton; the Institut universitaire de cardiologie et de pneumologie de Québec, Université Laval, Sainte-Foy, Quebec; and the University of Ottawa Heart Institute, Ottawa. These were all specialized centres, which had existing relationships with nonspecialized centres. We defined a specialized centre as a site with cardiac electrophysiology capabilities. We defined a nonspecialized centre as a site that provided cardiology care and follow-up but might or might not have had programming expertise for implantable cardioverter defibrillators.

We asked the following specific research questions: Is remote patient management feasible and generalizable in
Canadian device follow-up centres? Is remote patient management safe and effective to perform in Canadian device follow-up centres? Is the quality of life of patients improved by remote patient management in Canadian device follow-up centres? What cost savings to the health care system can be achieved through a program of remote patient management? Our hypotheses were that remote patient management is feasible and generalizable in Canadian device follow-up centres and that, at the pilot stage, it is safe and effective, that quality of life remains the same or is improved, and that cost savings can be potentially achieved.

\section{Participants}

To be eligible for enrolment, patients had to be 18 years of age or older, they had to be able to provide informed consent, and they had to have a CIED (cardioverter defibrillator or pacemaker) that could be monitored remotely (implanted de novo or already in place). Patients with implantable cardioverter defibrillators who received shared care at both a specialized site and a nonspecialized clinic were eligible. We approached patients in each of the 5 device clinics consecutively once eligibility was confirmed.

We excluded patients who were dependent on a pacemaker, defined as no underlying rhythm greater than 40 beats/min and no access to a cardiologist or specialist in their local community. ${ }^{27} \mathrm{We}$ also excluded patients with pacemakers who had no access to a smartphone, because the platform for remote monitoring required this technology.

\section{Intervention}

Patients with newly implanted devices were seen in clinic within 48 hours after the initial implant procedure and again within 3 months after the procedure. Over the 12 months of follow-up (the "after" period), no further in-clinic follow-up visits were scheduled. Additional follow-up in this period was conducted by remote monitoring, which involved transmission, via landline, cellular or wireless Internet connection, of device interrogations, describing device parameters and/or device events. These transmissions were delivered to each patient's specialized site for review by a cardiac electrophysiologist. Remote transmissions occurred on a scheduled basis every 6 months, with unscheduled transmissions occurring as needed. Unscheduled transmissions could be triggered actively by the patient or automatically by device-related events or parameters outside of programmed ranges.

Each patient was given a Medtronic CareLink remote monitoring system, and appropriate teaching was provided. Patient alerts were programmed as per the standard programming used at each participating site. Patients were not intended to travel outside of their local community for routine or unscheduled follow-up, even if device programming was required. If programming of an implantable cardioverter defibrillator was required, Medtronic Remote View technology was used, where approved (Queen Elizabeth II Health Sciences Centre, CK Hui Heart Centre and Université Laval). With this technology, health care providers at a specialized site can view the Medtronic programmer screen 
remotely, review the patient's information, recommend programming changes and communicate these changes to the nonspecialized site, all in real time. If programming was required for patients receiving care at the other 2 sites (Royal Jubilee Hospital or University of Ottawa Heart Institute), the patient was to be brought to the specialized site for programming to be performed in person.

\section{Data collection}

The research coordinators at each site performed a retrospective chart review to determine any events that occurred in each patient's "before" period. These research coordinators performed baseline data collection and administered quality-oflife questionnaires at the time of enrolment. The baseline data included eligibility criteria, sex, date of birth, device details, cardiac history, medications, and in-clinic and remote device interrogations. For the "after" period, the research coordinators completed 12-month follow-up by telephone, including documentation of cardiovascular hospitalizations, in-clinic device visits and quality-of-life questionnaires (for case report forms, see Appendix 1, Part A, available at www.cmajopen.ca/ content/9/1/E53/suppl/DC1). The adjudication committee (chair, R.P.; member, J.A.S.) reviewed cardiovascular hospitalizations, device-related events (ventricular arrhythmias and atrial high-rate episodes) and deaths. All adjudications were coded as per the case report form (see Appendix 1, Part A). The project manager performed data verification on $10 \%$ of charts (selected at random) to verify accuracy.

\section{Outcomes}

We evaluated the following outcomes: feasibility, defined as site implementation of remote patient management (including Remote View); patient adherence, defined as at least 1 successful remote transmission over the course of the study; safety, assessed in terms of occurrence of death, stroke, hospitalization for complications related to the device system and hospitalization for adverse cardiovascular events; ${ }^{22,23}$ and health care utilization as a before-after comparison. We assessed patients' quality of life $\mathrm{e}^{28-32}$ and costs. We also collected data about barriers to each of the elements that contributed to site implementation. Detailed definitions for these outcomes are provided in Appendix 1, Parts B and C.

The quality-of-life scales included the Florida Patient Acceptance Survey, which measures return to function since implantation, device-related distress, positive appraisal of the CIED and body image concerns related to having an implanted device ${ }^{30}$ the Florida Shock Anxiety Scale, which measures specific fears of defibrillator shocks and was administered only to the group with implantable cardioverter defibrillators; ${ }^{31,32}$ and the Medical Outcomes Study 36-item Short Form (SF-36). ${ }^{28}$ We compared quality of life between baseline and 12 months.

The analysis of costs to the health care system was based on fee codes from the Nova Scotia Medical Services Insurance manual. ${ }^{33}$ Costs associated with scheduled and unscheduled in-clinic visits consisted of 2 components: physician fees, which varied by type of device, and technician-related costs for in-clinic and remote interrogation. We calculated patients' costs according to the distance from the patient's community clinic to the specialized site. The relative cost savings reported here represent conservative estimates, because they do not include patients' out-of-pocket expenses and productivity losses, for which pertinent data were unavailable. We obtained all inpatient costs from the Canadian Institute for Health Information patient cost estimator.

\section{Statistical analysis}

We used descriptive statistics to summarize the demographic and clinical variables. We report continuous variables as means with standard deviations (SDs) and categorical variables as frequencies with percentages. We used $\mathrm{McNemar}$ tests to compare paired pre-post data on proportions of patients having a particular type of visit. We used the Kaplan-Meier survival method for a composite end point of death, cardiovascular hospitalization, device-related hospitalization and stroke. We applied mixed-model repeated-measures analysis to compare health-related quality-of-life variables from baseline to 12 -month follow-up. ${ }^{34}$ We report changes in quality-of-life variables using the least square mean with standard errors. We used box-and-whisker plots to show the change in quality-oflife variables from baseline to 12 -month follow-up. We considered $p$ values less than 0.05 to be significant. We performed all analyses with SAS version 9.4 software (SAS Institute Inc).

\section{Cost analysis}

We calculated the mean, SD, minimum and maximum cost values for patients who had at least 1 encounter. We used a generalized linear model, adjusted for age, the square of age and sex, to estimate expected total costs. We obtained the $95 \%$ confidence interval (CI) measuring uncertainty around each estimate from 1000 bootstrapped replications. We performed a counterfactual analysis based on the assumption that patients had to travel to the specialized monitoring clinic at least twice a year, in the absence of remote monitoring, keeping all other costs the same. Further details are presented in Appendix 1, Part C.

\section{Ethics approval}

We obtained ethics approval from the research ethics boards of participating centres: Nova Scotia Health Authority Research Ethics Board, Halifax; Health Research Ethics Board, University of Alberta, Edmonton; Centre de recherche de l'Institut universitaire de cardiologie et de pneumologie de Québec, Sainte-Foy; and Ottawa Health Science Network Research Ethics Board, Ottawa. Ethics approval was not received from the Victoria site; as such, we were unable to use Remote View technology at that location, and no data from that site were included in the analysis. We obtained informed consent from each patient who was enrolled.

\section{Results}

Of the 176 patients enrolled, 76 received a pacemaker (of whom 25 [33\%] had a de novo device), and 100 received an 
implantable cardioverter defibrillator (of whom 52 [52\%] had a de novo device) (Table 1, Table 2). Mean follow-up was 11.7 (SD 2.2) months. Of the 176 patients included in the study, 12 patients did not complete 12 month follow-up: 10 withdrew, 1 was removed from the study, and 1 was lost to follow-up (Figure 1).

A screening $\log$ was documented at 1 site, where 260 patients were approached; of these, a total of 56 (22\%) refused participation at that site. An additional 59 were excluded for other reasons. Results of the screening log are detailed in Appendix 1, Part D.

\section{Safety}

The composite end point of death, stroke, cardiovascular hospitalization or device-related hospitalization occurred in 12 (7\%) of the 164 participants who completed the 12 -month follow-up, counting the first event. Of 6 deaths, 2 were cardiovascular (nonarrhythmic), 3 were noncardiovascular, and 1 had unknown cause. Other major adverse events during the study were 1 stroke, 7 emergency department visits for cardiovascular causes, 1 hospital admission for electrical storm and 5 cardiovascular hospital admissions.

\section{Implementation and adherence}

Three of the 5 sites were able to implement remote programming capability using the Remote View software and satisfying all requirements for implementation (Appendix 1, Part B). For the other 2 sites, institutional privacy policies prevented approval for implementation of Remote View software; these 2 sites were able to implement remote-only follow-up without remote programming.

Of the 176 patients, 153 (87\%) were adherent to remote monitoring follow-up. Of these, 85 (85\%) of the 100 patients with a defibrillator and $68(89 \%)$ of the 76 patients with a pacemaker had at least 1 remote transmission during the study and were considered adherent.

\section{Health care utilization}

In total, 99 patients were eligible for the before-after comparison: 48 with defibrillators and 51 with pacemakers. Among the 48 patients with defibrillators, there was a significant reduction in the proportion who had any type of in-clinic visit (36 [75\%] before v. 21 [44\%] after, $p<0.001$ ) (Figure 2), which was predominantly due to a significant reduction in visits to specialized sites (26 [54\%] v. $5[10 \%], p<0.001)$ (Appendix 1, Part E). For the patients with defibrillators, there was no change in visits to nonspecialized sites (13 [27\%] v. $17[35 \%], p=0.3)$ or in remote transmissions (44 [92\%] v. $43[90 \%], p=0.7$ ) (Figure 2). Among the 51 patients with pacemakers, the proportion with in-clinic visits declined (42 [82\%] before v. 10 [20\%] after, $p<0.001$ ), and the proportion with remote transmissions increased (2 [4\%] v. 43 [84\%], $p<0.001$ ) (Figure 2). Time to the first transmission averaged 6.8 (SD 3.8) months for patients with pacemakers $(n=56)$ and 5.6 (SD 3.2) months for patients with defibrillators $(n=81)$.

A total of 100 device visits occurred during the study. Of these, 78 involved patients with defibrillators, whose reasons
Table 1: Baseline characteristics of patients with pacemakers

\begin{tabular}{cc|}
\hline & No. (\%) of patients* \\
$n$ & $=76$
\end{tabular}

\begin{tabular}{|lc}
\hline Age, yr, mean \pm SD & $63.4 \pm 16.5$ \\
\hline Time since implant, yr, mean \pm SD & $2.7 \pm 3.2$ \\
\hline Sex, female & $28(37)$ \\
\hline
\end{tabular}

Cardiovascular history

Ischemic heart disease $13(17)$

Nonischemic heart disease $5(7)$

Hypertrophic obstructive cardiomyopathy 1 (1)

Arrhythmogenic right ventricular 0 cardiomyopathy

Atrial fibrillation or flutter 28 (37)

Stroke or transient ischemic attack $3(4)$

Valvular disease $13(17)$

Primary electrical disease $\quad 7$ (9)

Medications

\begin{tabular}{ll} 
Diuretic & $17(22)$ \\
\hline & $19(25)$
\end{tabular}

Antiarrhythmic 4 (5)

Antiplatelet $23(30)$

Nitrates 2 (3)

Oral anticoagulant $21(28)$

Statin 22(29)

$\beta$-Blocker 24 (32)

Calcium-channel blocker $13(17)$

Digoxin 4 (5)

Indication for pacemaker

\begin{tabular}{lc} 
AV nodal disease & $24(32)$ \\
\hline Sinus node dysfunction & $29(38)$ \\
Syncope & $19(25)$ \\
\hline Other & $4(5)$ \\
Cardiac resynchronization therapy device & $1(1)$
\end{tabular}

No. of implanted leads (active and

inactive)

\begin{tabular}{|cc|}
\hline 1 & $11(14)$ \\
\hline 2 & $62(82)$ \\
\hline 3 & $3(4)$ \\
\hline 4 & 0 \\
\hline
\end{tabular}

Note: $\mathrm{ACE}=$ angiotensin-converting enzyme, $\mathrm{ARB}=$ angiotensin II receptor blocker, $\mathrm{AV}=$ atrioventricular, $\mathrm{SD}=$ standard deviation.

${ }^{\star}$ Except where indicated otherwise.

for presentation were as follows: shock $(n=6)$, syncope $(n=$ $1)$, alert $(n=4)$, dyspnea $(n=1)$, routine $(n=45)$ and other $(n=$ 21) (Appendix 1, Part F). The remaining 22 visits involved patients with pacemakers for the following reasons: chest pain $(n=1)$, routine $(n=11)$ and other $(n=10)$ (Appendix 1, Part F). There were 27 device-detected events. A total of 9 patients 
Table 2: Baseline characteristics of patients with ICD

\begin{tabular}{|c|c|}
\hline Characteristic & $\begin{array}{l}\text { No. }(\%) \text { of patients } \\
\qquad \begin{array}{l}n=100\end{array}\end{array}$ \\
\hline Age, yr, mean \pm SD & $62.5 \pm 11.8$ \\
\hline Time since implant, yr, mean \pm SD & $2.0 \pm 2.3$ \\
\hline Sex, female & $29(29)$ \\
\hline \multicolumn{2}{|l|}{ Cardiovascular history } \\
\hline Ischemic heart disease & $55(55)$ \\
\hline Nonischemic heart disease & $27(27)$ \\
\hline Hypertrophic obstructive cardiomyopathy & $5(5)$ \\
\hline $\begin{array}{l}\text { Arrhythmogenic right ventricular } \\
\text { cardiomyopathy }\end{array}$ & $1(1)$ \\
\hline Atrial fibrillation or flutter & $14(14)$ \\
\hline Stroke or transient ischemic attack & $3(3)$ \\
\hline Valvular disease & $2(2)$ \\
\hline Primary electrical disease & $4(4)$ \\
\hline \multicolumn{2}{|l|}{ Medications } \\
\hline ACE inhibitor/ARB & $51(51)$ \\
\hline Diuretic & $47(47)$ \\
\hline Antiarrhythmic & $11(11)$ \\
\hline Antiplatelet & $68(68)$ \\
\hline Nitrates & $20(20)$ \\
\hline Oral anticoagulant & $25(25)$ \\
\hline Statin & $68(68)$ \\
\hline$\beta$-Blocker & $88(88)$ \\
\hline Calcium-channel blocker & $11(11)$ \\
\hline Digoxin & $4(4)$ \\
\hline \multicolumn{2}{|l|}{ Indication for ICD } \\
\hline Primary prevention & $55(55)$ \\
\hline Secondary prevention & $45(45)$ \\
\hline Cardiac resynchronization therapy device & $13(13)$ \\
\hline \multicolumn{2}{|l|}{$\begin{array}{l}\text { No. of implanted leads (active and } \\
\text { inactive) }\end{array}$} \\
\hline 1 & $52(52)$ \\
\hline 2 & $31(31)$ \\
\hline 3 & $15(15)$ \\
\hline 4 & $2(2)$ \\
\hline $\begin{array}{l}\text { Note: } \mathrm{ACE}=\text { angiotensin-converting enzyme, } \mathrm{ARB}=\text { an } \\
\text { blocker, ICD = implantable cardioverter defibrillator, } \mathrm{SD} \\
{ }^{*} \text { Except where indicated otherwise. }\end{array}$ & $\begin{array}{l}\text { giotensin II receptor } \\
\text { = standard deviation. }\end{array}$ \\
\hline
\end{tabular}

with implantable cardioverter defibrillators experienced appropriate shocks $(n=5)$ or antitachycardia pacing $(n=4)$. Episodes of atrial high rate were found in 10 patients, and 1 patient with a pacemaker experienced a sustained ventricular arrhythmia that necessitated insertion of a defibrillator. We did not observe any negative outcomes relating to implementation of remote monitoring, with or without remote programming.

\section{Remote View technology}

In total, 6 Remote View visits were performed during the study. Two of these sessions could not be successfully completed because of technical issues. These 2 patients were managed remotely in conjunction with the nonspecialized site. The remaining 4 successful remote visits were conducted for the following reasons: 2 for shocks and 2 for early postimplant interrogations. Each of these visits replaced at least $200 \mathrm{~km}$ of round-trip travel for patients.

\section{Quality of life}

The Florida Patient Acceptance Survey did not show any significant changes in positive appraisal, return to function or body image concern between baseline and 12 months (Appendix 1, Parts G-I). For patients with a defibrillator, the Florida Shock Anxiety Scale did not show a significant difference between 0 and 12 months (Appendix 1, Parts $\mathrm{J}$ and K). The SF-36 survey results did not show any clinically significant improvement in mental score (Appendix 1, Part L).

\section{Costs}

With our cost analysis (Table 3), we estimated that a program of remote patient management reduced patient health care costs by 31\% (\$660 [95\% CI \$642-\$679] saved per patientyear) for patients with implantable cardioverter defibrillators and by 44\% (\$86 [95\% CI \$86-\$87] saved per patient-year) for those with pacemakers. Data for patient travel costs suggested a larger proportional saving, with estimated travel costs saved of 92\% for patients with defibrillators (\$358 [95\% CI \$299-\$418] per patient-year) and 89\% (\$8 [95\% CI \$7-\$8] saved per patient-year) for patients with pacemakers. These estimates do not include societal costs or patient opportunity costs arising from travel.

\section{Interpretation}

In this study, we found that remote-only follow-up was feasible and reduced health care utilization, with preliminary data suggesting that it is safe, effective and generalizable to the current Canadian population with CIEDs. However, the study failed to show the feasibility of implementing Remote View technology in all of the centres that were enrolled in the study, given that only 3 of the 5 centres approved its use. The barriers to use of Remote View technology related primarily to privacy concerns within the institutions where it was to be implemented. Nonetheless, remote-only follow-up was associated with a reduction in health care utilization, including a substantial reduction of in-clinic visits and reduced costs without any signal for lack of safety or reduction in quality of life.

Prior studies have established the benefit of remote monitoring in improving CIED outcomes and decreasing costs without any signal for increased adverse events. ${ }^{35-38} \mathrm{In}$ all of these prior studies, with the exception of COMPAS, ${ }^{35}$ remote monitoring was combined with in-clinic visits. The REMOTE-CIED study examined the effect of remote-only follow-up with a single in-clinic visit, relative to standard frequency of in-clinic visits (every $3 \mathrm{mo}$ ), and found no 


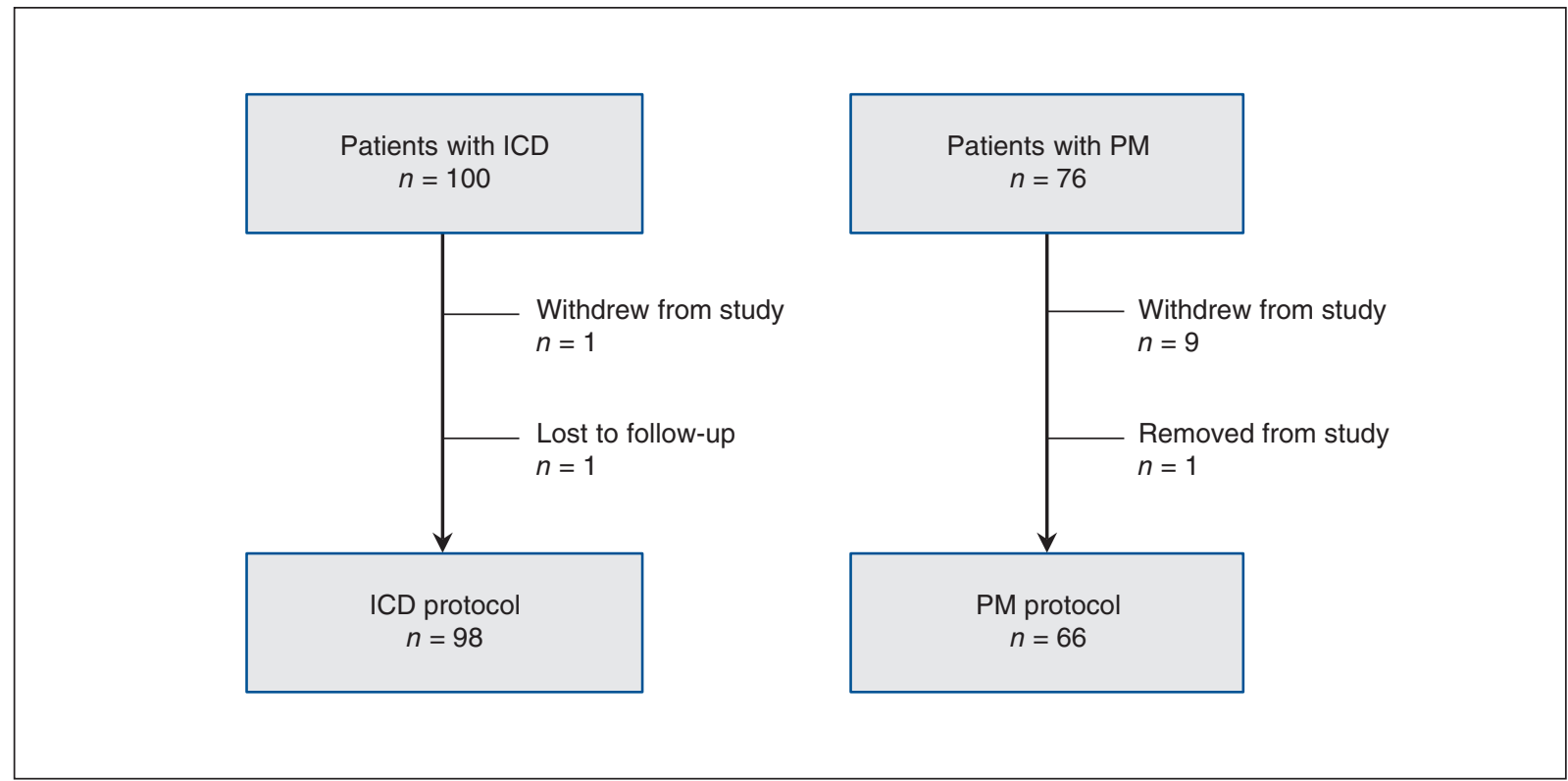

Figure 1: Patient flow. The total number of patients approached to participate in the pilot study is not available because some of the centres did not keep a screening log. Of patients with pacemakers, 1 was removed from the study (because the device was replaced with an implantable cardioverter defibrillator), and 9 withdrew from the study for the following reasons: none given $(n=3)$, preferred in-clinic visits or already coming in for other appointments $(n=3)$, progressing cognitive impairment due to Alzheimer disease $(n=1)$, not comfortable with the technology $(n=1)$ and unable to be home for delivery of remote monitoring paddle $(n=1)$. Note: $I C D=$ implantable cardioverter defibrillator, $\mathrm{PM}=$ pacemaker.

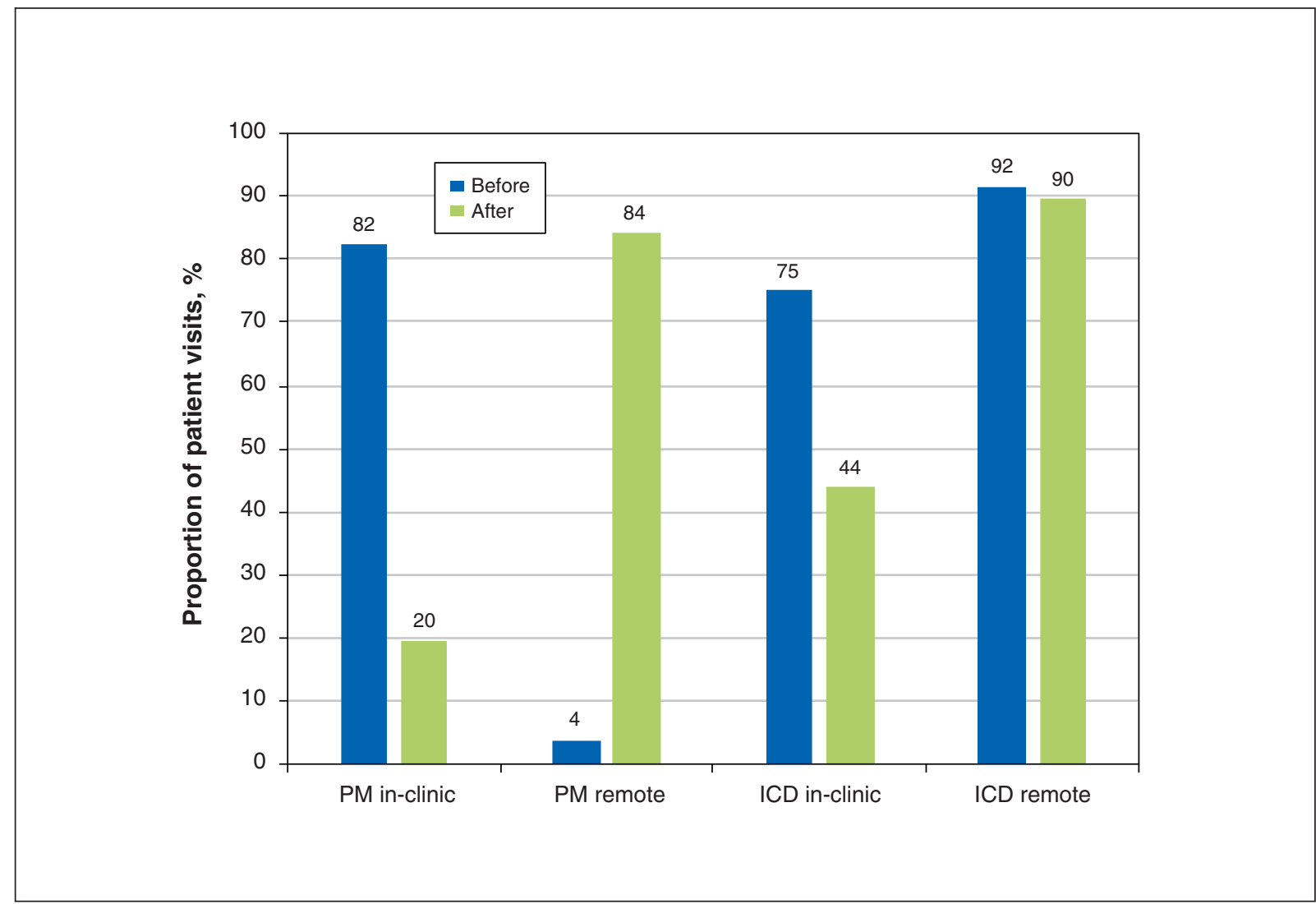

Figure 2: In-clinic and remote visits before and after implementation of remote patient management. After implementation, in-clinic visits decreased $(p<0.001)$ and remote visits increased $(p<0.001)$ for patients with pacemakers (PMs; $n=51)$, whereas in-clinic visits decreased for patients with implantable cardioverter defibrillators (ICDs; $n=48 ; p<0.001$ ). 
Table 3: Cost analysis of remote-only monitoring

\begin{tabular}{|c|c|c|}
\hline \multirow[b]{2}{*}{ Element of cost } & \multicolumn{2}{|c|}{ Device; mean cost, \$ (95\% Cl) } \\
\hline & Implantable cardioverter defibrillator & Pacemaker \\
\hline \multicolumn{3}{|l|}{ Health care } \\
\hline Actual total costs & 1469 (1379-1559) & $112(81-143)$ \\
\hline Counterfactual total costs* & $2130(2044-2215)$ & $199(167-230)$ \\
\hline Total savings & $660(642-679)$ & $86(86-87)$ \\
\hline \multicolumn{3}{|l|}{ Travel } \\
\hline Actual costs & $33(13-53)$ & $1(1-2)$ \\
\hline Counterfactual costs* & $391(339-444)$ & $9(8-10)$ \\
\hline Cost savings & $358(299-418)$ & $8(7-8)$ \\
\hline
\end{tabular}

difference in quality of life. ${ }^{36}$ The REFORM trial reported on 155 patients with primary prevention defibrillators and found that yearly in-clinic visits with remote monitoring significantly reduced the burden of defibrillator follow-up, with no increased signal in safety outcomes. ${ }^{37}$ In a study of 1274 patients with pacemakers in Japan, remote-only monitoring was noninferior to biannual in-clinic follow-up for a composite of death, stroke and cardiovascular events requiring surgery. ${ }^{38}$ In addition, only $1.4 \%$ of remote follow-ups triggered an unscheduled in-clinic follow-up, which resulted in significant cost savings. ${ }^{38}$ These studies reported findings similar to those of our study; however, we also found that no scheduled in-clinic visits outside of a patient's local community were required, which differs from 2 of these studies. ${ }^{36,37}$

The need to improve care related to device follow-up is urgent, given the important impact of such care on patients living with these devices. Some patients may not accept device therapy if follow-up cannot be arranged within their local community. Refusal of defibrillator therapy has been associated with increased mortality. ${ }^{39}$ Geographic barriers to attending in-clinic visits exist globally, and improvements in remote monitoring can help to overcome these barriers. Finally, the burden of remote monitoring on clinical workload needs to be relieved by reducing in-clinic visits that may be unnecessary.

The follow-up schedule that is currently part of device guidelines is based on earlier models that traditionally were less reliable and had few or no automated algorithms to ensure functionality and safety. A change in follow-up practices is warranted to accommodate the increased utilization of more recent models of these devices.

In addition, improved communication with patients regarding the status of their device as determined through remote monitoring is needed. For example, in a survey of 512 patients with devices, $91 \%$ reported that they would like to have information on the outcome of their remote monitoring transmissions. ${ }^{26}$

\section{Limitations}

The limitations of our study included the short duration of follow-up and the cohort design. Although the study results indicated that use of Remote View technology was not feasible, they did show the value and safety of remote-only follow-up, without any compromise of quality of life. Privacy evaluations at some centres prevented implementation of the software. However, given that this software was a small component of the study, this limitation does not prevent further pursuit of this line of inquiry.

We compared quality of life at baseline and 12 months, not before and after implementation of remote-only monitoring, which led to difficulty in ascertaining which factors might be affecting quality of life. However, it is important to report and measure quality of life in the overall group to ensure that remote monitoring alone did not impair patients' quality of life relative to baseline.

The cost analysis in this pilot study has provided only preliminary data, and the findings should be interpreted with caution. Costs related to device follow-up were considered from only 1 province (Nova Scotia), and fee structures differ among the provinces. Costs were estimated, not measured directly, so the cost data are likely underestimates. More detailed cost analysis would be required to permit a more accurate prediction of potential cost savings. However, our cost findings concur with the results of prior studies. In the Effectiveness and Cost of Defibrillator Follow-up Schedule with Telecardiology (ECOST) trial, the costs were $13 \%$ lower in the remote monitoring group than in the control group. ${ }^{40}$ This corresponded to a decrease of $€ 257$ (95\% CI $€ 5-€ 489, p=0.004$ ) in costs per patient-year, attributable to remote monitoring. In a systematic review, Health Quality Ontario estimated that a publicly funded remote monitoring system would result in $\$ 14$ million savings over the first 5 years. ${ }^{41}$

Poor acceptance of remote management by patients was an important limitation, in that $14 \%$ of patients who were approached for participation wanted to continue travelling to 
the specialized centre for follow-up. This highlights the importance to patients of continued access to specialized care and the need to ensure that they are able to communicate with these centres, even if they are being followed through remote monitoring.

A larger study incorporating and building upon these findings may provide the necessary evidence that remote-only follow-up is patient-centred but also the optimal method to provide excellent device care. The Cardiac Arrhythmia Network has incorporated these findings, to create a virtual solution to these problems, as an enhancement to currently established remote monitoring practices. This solution is currently begin tested as part of 2 ongoing clinical trials. ${ }^{42,43}$

Transmission reports were reviewed as per clinical practice at each centre; this review was independent of the study investigators. However, there was overlap between the cardiac electrophysiologists at the participating centres and the adjudication committee.

\section{Conclusion}

A follow-up strategy involving only remote monitoring was found to be feasible, safe and effective, with potential cost savings for patients with CIEDs, without detrimental effects on quality of life. Privacy policies remain a hurdle to the implementation of Remote View software, in conjunction with remote monitoring of devices. Further research to optimize expansion of this approach to follow-up could result in a major shift in remote monitoring in CIED care, with reduced costs to the health care system and increased patient convenience.

\section{References}

1. Fraser JD, Gillis AM, Irwin ME, et al. Guidelines for pacemaker follow-up in Canada: a consensus statement of the Canadian Working Group on Cardiac Pacing. Can 7 Cardiol 2000;16:355-63, 367-76.

2. Gillis AM, Philippon F, Cassidy MR, et al. Guidelines for implantable cardioverter defibrillator follow-up in Canada: a consensus statement of the Canadian Working Group on Cardiac Pacing. Can 7 Cardiol 2003;19:21-37.

3. Yee R, Verma A, Beardsall M, et al. Canadian Cardiovascular Society/ Canadian Heart Rhythm Society joint position statement on the use of remote monitoring for cardiovascular implantable electronic device followup. Can 7 Cardiol 2013;29:644-51.

4. Wilkoff BL, Auricchio A, Brugada J, et al. HRS/EHRA expert consensus on the monitoring of cardiovascular implantable electronic devices (CIEDs): description of techniques, indications, personnel, frequency and ethical considerations. Heart Rhythm 2008;5:907-25.

5. Hauck M, Bauer A, Voss F, et al. "Home monitoring" for early detection of implantable cardioverter-defibrillator failure: a single-center prospective observational study. Clin Res Cardiol 2009;98:19-24.

6. Joseph GK, Wilkoff BL, Dresing T, et al. Remote interrogation and monitoring of implantable cardioverter defibrillators. 7 Interv Card Electrophysiol 2004;11:161-6.

7. Lazarus A. Remote, wireless, ambulatory monitoring of implantable pacemakers, cardioverter defibrillators, and cardiac resynchronization therapy systems: analysis of a worldwide database. Pacing Clin Electrophysiol 2007;30Suppl 1):S2-12

8. Marzegalli M, Lunati M, Landolina M, et al. Remote monitoring of CRTICD: the multicenter Italian CareLink evaluation - ease of use, acceptance, and organizational implications. Pacing Clin Electrophysiol 2008;31:1259-64.

9. Nielsen JC, Kottkamp H, Zabel M, et al. Automatic home monitoring of implantable cardioverter defibrillators. Europace 2008;10:729-35.

10. Raatikainen MJ, Uusimaa P, van Ginneken MM, et al. Remote monitoring of implantable cardioverter defibrillator patients: a safe, time-saving, and costeffective means for follow-up. Europace 2008;10:1145-51.

11. Ricci RP, Morichelli L, Quarta L, et al. Long-term patient acceptance of and satisfaction with implanted device remote monitoring. Europace 2010;12:674-9.

12. Ricci RP, Morichelli L, Santini M. Remote control of implanted devices through home monitoring technology improves detection and clinical management of atrial fibrillation. Europace 2009;11:54-61.
13. Ricci RP, Morichelli L, Santini M. Home monitoring remote control of pacemaker and implantable cardioverter defibrillator patients in clinical practice: impact on medical management and health-care resource utilization. Europace 2008;10:164-70.

14. Sacher F, Probst V, Bessouet M, et al. Remote implantable cardioverter defibrillator monitoring in a Brugada syndrome population. Europace 2009;11:489-94.

15. Schoenfeld MH, Compton SJ, Mead RH, et al. Remote monitoring of implantable cardioverter defibrillators: a prospective analysis. Pacing Clin Electrophysiol 2004;27:757-63.

16. Theuns DA, Rivero-Ayerza M, Knops P, et al. Analysis of 57148 transmissions by remote monitoring of implantable cardioverter defibrillators. Pacing Clin Electrophysiol 2009;32(Suppl 1):S63-5.

17. Varma N, Stambler B, Chun S. Detection of atrial fibrillation by implanted devices with wireless data transmission capability. Pacing Clin Electrophysiol 2005;28(Suppl 1):S133-6.

18. Crossley GH, Chen J, Choucair W, et al. Clinical benefits of remote versus transtelephonic monitoring of implanted pacemakers. $7 \mathrm{Am}$ Coll Cardiol 2009;54:2012-9.

19. Halimi F, Clementy J, Attuel P, et al. Optimized post-operative surveillance of permanent pacemakers by home monitoring: the OEDIPE trial. Europace 2008;10:1392-9.

20. Al-Khatib SM, Piccini JP, Knight D, et al. Remote monitoring of implantable cardioverter defibrillators versus quarterly device interrogations in clinic: results from a randomized pilot clinical trial. 7 Cardiovasc Electrophysiol 2010;21:545-50

21. Bikou O, Licka M, Kathoefer S, et al. Cost savings and safety of ICD remote control by telephone: a prospective, observational study. 7 Telemed Telecare 2010;16:403-8.

22. Crossley GH, Boyle A, Vitense H, et al. The CONNECT (Clinical Evaluation of Remote Notification to Reduce Time to Clinical Decision) trial: the value of wireless remote monitoring with automatic clinician alerts. $7 \mathrm{Am}$ Coll Cardiol 2011;57:1181-9.

23. Varma N, Epstein AE, Irimpen A, et al. Efficacy and safety of automatic remote monitoring for implantable cardioverter-defibrillator follow-up: the Lumos-T Safely Reduces Routine Office Device Follow-up (TRUST) trial. Circulation 2010;122:325-32.

24. Gillis AM. Expert commentary: How well has the call from Heart Rhythm Society/European Heart Rhythm Association for improved device monitoring been answered? Europace 2013;15(Suppl 1):i32-4.

25. Halimi F, Cantù F; European Heart Rhythm Association Scientific Initiatives Committee. Remote monitoring for active cardiovascular implantable electronic devices: a European survey. Europace 2010;12:1778-80.

26. Kelly SE, Campbell D, Duhn LJ, et al. Remote monitoring of cardiovascular implantable electronic devices in Canada: survey of patients and device healthcare professionals CFC Open 2020 Nov. 19. Epub ahead of print. doi: 10.1016/j.cjco.2020.11.010.

27. Tang AS, Roberts RS, Kerr C, et al. Relationship between pacemaker dependency and the effect of pacing mode on cardiovascular outcomes. Circulation 2001;103:3081-5.

28. Ware JE, Snow KK, Kosinski M, et al. SF-36 bealth survey: manual and interpretation guide. Boston: The Health Institute New England Medical Center; 1993.

29. Brazier JE, Harper R, Jones NM, et al. Validating the SF-36 health survey questionnaire: new outcome measure for primary care. BMF 1992;305:160-4.

30. Burns JL, Serber ER, Keim S, et al. Measuring patient acceptance of implantable cardiac device therapy: initial psychometric investigation of the Florida Patient Acceptance Survey. 7 Cardiovasc Electrophysiol 2005;16:384-90.

31. Ford J, Finch JF, Woodrow LK, et al. The Florida Shock Anxiety Scale (FSAS) for patients with implantable cardioverter defibrillators: testing factor structure, reliability, and validity of a previously established measure. Pacing Clin Electrophysiol 2012;35:1146-53.

32. Kuhl EA, Dixit NK, Walker RL, et al. Measurement of patient fears about implantable cardioverter defibrillator shock: an initial evaluation of the Florida Shock Anxiety Scale. Pacing Clin Electrophysiol 2006;29:614-8.

33. Physician's manual 2014. Dartmouth (NS): Nova Scotia Medical Services Insurance; 2014. Available: www.medavie.bluecross.ca/static/MSI/PhysicianManual. pdf (accessed 2019 Dec. 1).

34. Zou B, Jin B, Koch GG, et al. On model selections for repeated measurement data in clinical studies. Stat Med 2015;34:1621-33.

35. Mabo P, Victor F, Bazin P, et al. A randomized trial of long-term remote monitoring of pacemaker recipients (the COMPAS trial). Eur Heart 7 2012;33:1105-11.

36. Versteeg H, Timmermans I, Widdershoven J, et al. Effect of remote monitoring on patient-reported outcomes in European heart failure patients with an implantable cardioverter-defibrillator: primary results of the REMOTECIED randomized trial. Europace 2019;21:1360-8.

37. Hindricks G, Elsner C, Piorkowski C, et al. Quarterly vs. yearly clinical followup of remotely monitored recipients of prophylactic implantable cardioverterdefibrillators: results of the REFORM trial. Eur Heart 7 2014;35:98-105.

38. Watanabe E, Yamazaki F, Goto T, et al. Remote management of pacemaker patients with biennial in-clinic evaluation: continuous home monitoring in 
the Japanese At-Home study: a randomized clinical trial. Circ Arrbythm Electrophysiol 2020;13:e007734.

39. Parkash R, Wightman H, Miles G, et al. Primary prevention of sudden cardiac death with device therapy in urban and rural populations. Can 7 Cardiol 2017;33:437-42.

40. Guédon-Moreau L, Lacroix D, Sadoul N, et al. Costs of remote monitoring vs. ambulatory follow-ups of implanted cardioverter defibrillators in the randomized ECOST study. Europace 2014;16:1181-8.

41. Health Quality Ontario. Remote monitoring of implantable cardioverterdefibrillators, cardiac resynchronization therapy and permanent pacemakers: a health technology assessment. Ont Health Technol Assess Ser 2018;18:1-199.

42. Remote patient management of CIEDs (RPM CIED Tachy). ClinicalTrials.gov: NCT03405740; 2018 [updated 2020 July 22]. Available: https://clinicaltrials. gov/ct2/show/NCT03405740 (accessed 2021 Jan. 7).

43. Remote patient management of CIEDs - brady devices (RPM CIED Brady). CinicalTrials.gov: NCT03636230; 2018 [updated 2020 Oct. 29]. Available: https://clinicaltrials.gov/ct2/show/NCT03636230 (accessed 2021 Jan. 7).

Affiliations: QEII Health Sciences Centre, Dalhousie University (Sapp, AbdelWahab, Parkash), Halifax, NS; Department of Cardiac Sciences (Gillis, Raj), University of Calgary, Calgary, Alta.; Institut universitaire de cardiologie and pneumologie de Quebec (Nault, Philippon), Université Laval, Québec, Que.; University of Ottawa Heart Institute (Nery, Wells), Ottawa, Ont.; Hamilton Health Sciences (Healey), McMaster University, Hamilton, Ont.; CK Hui Heart Centre (Lockwood), Edmonton, Alta.; Vancouver Island Health Authority (Sterns), Victoria, BC; East Carolina University (Sears), Greenville, NC; London Health Sciences Centre (Yee, Tang), University of Western Ontario, London, Ont.

Contributors: Anne Gillis, Amir AbdelWahab, Isabelle Nault, Pablo Nery, Jeff Healey, Satish Raj, Evan Lockwood, Laurence Sterns, George Wells, Raymond Yee, François Philippon, Anthony Tang and Ratika
Parkash conceived the idea for the study and secured research funding. All of the authors supervised data collection and interpretation of the analysis. Samuel Sears was responsible for the quality-of-life scales and their analysis and interpretation. George Wells conducted the statistical analyses. John Sapp and Ratika Parkash drafted the manuscript. All of the authors supervised the conduct of the trial and data collection, contributed to revision of the manuscript, approved the final version for publication and agreed to be accountable for the work.

Funding: This work was supported by the Cardiac Arrhythmia Network, in conjunction with Medtronic Canada.

Content licence: This is an Open Access article distributed in accordance with the terms of the Creative Commons Attribution (CC BY-NCND 4.0) licence, which permits use, distribution and reproduction in any medium, provided that the original publication is properly cited, the use is noncommercial (i.e., research or educational use), and no modifications or adaptations are made. See: https://creativecommons.org/licenses/ by-nc-nd/4.0/

Data sharing: The authors do not have consent from patients or hospital research ethics boards to share individual case data. However, upon request, they will make summary data available to other investigators.

Acknowledgements: The authors would like to acknowledge Karen Giddens for project management, Li Chen for statistical analysis and Prosper Koto for economic analysis.

Supplemental information: For reviewer comments and the original submission of this manuscript, please see www.cmajopen.ca/content/9/1/ E53/suppl/DC1. 